\title{
Images in Anesthesia: Transesophageal echocardiogram (TEE) images of an anomalous left circumflex coronary artery.
}

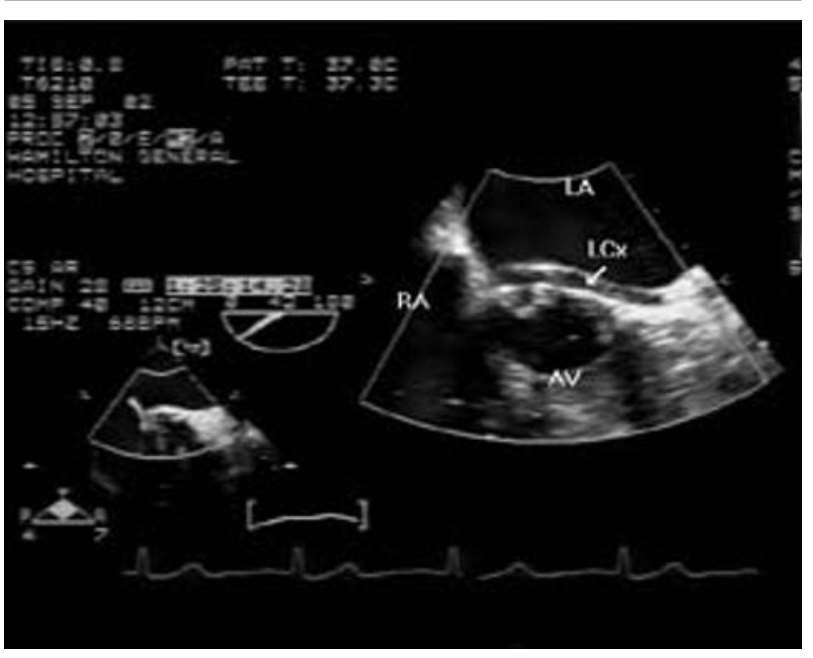

FIGURE 1 Intraoperative transesophageal echocardiogram image of the anomalous left circumflex artery (LCx). Left atrium (LA), right atrium (RA), aortic valve (AV).

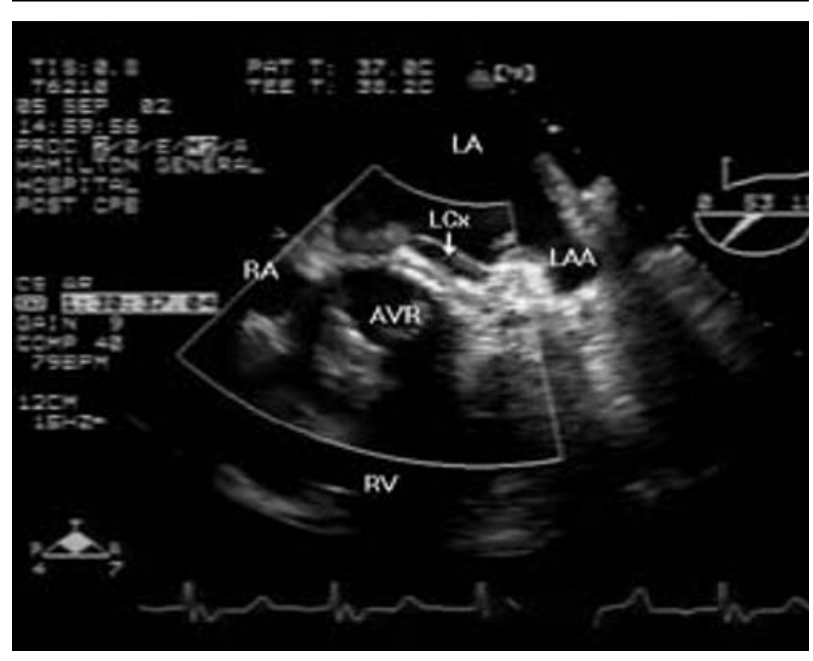

FIGURE 2 Post-AVR transesophageal echocardiogram image of the anomalous left circumflex artery (LCx), showing colour flow Doppler in the vessel. Left atrium (LA), right atrium (RA), left atrial appendage (LAA), right ventricle (RV), aortic valve replacement (AVR).

Anomalous coronary arteries may be identified with TEE. ${ }^{1}$ Occlusion of such an anomalous coronary artery can occur during aortic valve replacement by deeply placed sutures or by compression from a prosthetic ring. ${ }^{2}$ Intraoperative TEE may be useful to assess the patency of this vessel after aortic valve surgery.

Andrew Roscoe FrCA

Ashraf Fayad FCARCSI

Corey Sawchuk FRCPC

Hamilton, Ontario

\section{References}

1 Fernandes F, Alam M, Smith S, Khaja F. The role of transesophageal echocardiography in identifying anomalous coronary arteries. Circulation 1993; 88: 2532-40.

$2 O^{\prime}$ Blenes SB, Feindel CM. Aortic root replacement with anomalous origin of the coronary arteries. Ann Thorac Surg 2002; 73: 647-9. 